\title{
Cancer research in the 57 Organisation of Islamic Cooperation (OIC) countries, 2008-17
}

\author{
Grant Lewison ${ }^{1}$, Shoaib Fahad Hussain², Ping Guo ${ }^{3,4}$, Richard Harding ${ }^{4}$, Deborah Mukherji5, Ghassan Abu Sittah ${ }^{6}$, Ajay Aggarwal ${ }^{7}$, Fouad \\ Fouad $^{8}$, Nirmala Bhoo-Pathy ${ }^{9}$, Omar Shamieh ${ }^{10,11}$, Julie Torode ${ }^{12}$, Tezer Kutluk ${ }^{13}$ and Richard Sullivan ${ }^{14}$ on behalf of R4HC partnership
}

${ }^{1}$ King's College London, Institute for Cancer Policy, Guy's Hospital, Great Maze Pond, London SE1 9RT, UK

${ }^{2}$ Conflict and Health Research Group, School of Security Studies, King's College London, London SE1 9RT, UK

${ }^{3}$ School of Nursing, College of Medical and Dental Sciences, University of Birmingham, Edgbaston, Birmingham B15 2TT, UK

${ }^{4}$ Florence Nightingale Faculty of Nursing, Midwifery and Palliative Care, Cicely Saunders Institute, King's College London, London SE 9PJ, UK

${ }^{5}$ American University of Beirut Medical Center, Beirut, Lebanon

${ }^{6}$ American University of Beirut, Global Health Institute, Beirut, Lebanon

${ }^{7}$ King's College London, Institute for Cancer Policy, Guy's Hospital, Great Maze Pond, London SE1 9RT, UK

${ }^{8}$ American University of Beirut, Faculty of Health Science, Beirut, Lebanon

${ }^{9}$ Centre for Epidemiology and Evidence-Based Practice, Faculty of Medicine, University of Malaya, 50603, Lembah Pantai, Kuala Lumpur, Malaysia

${ }^{10}$ King Hussein Cancer Centre, Amman, Jordan

${ }^{11}$ School of Medicine, the University of Jordan, Amman, Jordan

${ }^{12}$ Union for International Cancer Control (UICC), Avenue Giuseppe Motta 31-33, 1202, Geneva, Switzerland

${ }^{13}$ Haceteppe University, Ankara 06100, Turkey

${ }^{14}$ King's College London, Institute for Cancer Policy, Guy's Hospital, Great Maze Pond, London SE1 9RT, UK

\section{Abstract}

Background and objectives: The 57 countries of the Organisation of Islamic Cooperation (OIC) are experiencing rapid increases in their burden of cancer. The First Ladies Against Cancer meeting at the 2016 OIC meeting in Istanbul committed to the importance of cancer control and the need for more evidence to support national cancer control planning (NCCP). Strong research systems are a crucial aspect of NCCP, but few data exist to support policy-makers across this political grouping

Methodology: We identified all cancer research papers from OIC countries in the Web of Science from 2008 to 2017 with a filter based on journal names and title words, with high precision and recall. We analysed the country outputs, the cancer sites investigated, the types of research, sources of funding and the citations to the papers.

Results: There were 49,712 cancer research papers over this period. The leading countries in terms of output were Turkey, Iran, Egypt and Malaysia, but the most cited papers were from Qatar, Indonesia and Saudi Arabia. International collaboration was low, except in Qatar and the United Arab Emirates. The site-specific cancers accounting for most research were breast and blood, correlating with their disease burden in the OIC countries, but lung, cervical and oesophageal cancers were relatively under-researched. Most funding from within the OIC countries was from their own university sector.

Conclusion: Cancer is seriously under-researched in most of the OIC countries. This will undermine the ability of these countries and OIC as a whole to deliver on better cancer control for their populations. New policies, OIC leadership and funding are urgently needed to address this situation.

\author{
Correspondence to: Grant Lewison \\ Email: grantlewison@aol.com \\ ecancer 2020, 14:1094 \\ https://doi.org/10.3332/ecancer.2020.1094 \\ Published: $28 / 08 / 2020$ \\ Received: $15 / 07 / 2020$ \\ Publication costs for this article were supported by \\ ecancer (UK Charity number 1176307). \\ Copyright: (c) the authors; licensee \\ ecancermedicalscience. This is an Open Access \\ article distributed under the terms of the \\ Creative Commons Attribution License (http:// \\ creativecommons.org/licenses/by/3.0), which \\ permits unrestricted use, distribution, and \\ reproduction in any medium, provided the original \\ work is properly cited.
}


Keywords: cancer research, Organisation of Islamic Cooperation, cancer anatomical sites, research types, funding, citations

\section{Introduction}

The Organisation of Islamic Cooperation (OIC) is the second largest intergovernmental organisation after the United Nations (UN) with a membership of 57 countries and 5 observer states across four continents, but primarily in Asia and Africa (27 in each), as shown in Table 1. The OIC aims to represent the collective political and socio-economic interests of the Muslim world [1, 2]. The organisation also includes efforts to enhance cooperation between member states in healthcare, technology, research and development and education although it does not have a specific focus on cancer control [3]. OIC member states collectively constitute over 1.8 billion people, i.e., approximately $23 \%$ of the world's population. With a population growth rate of $1.86 \%$ between 2010 and 2015 , this proportion is projected to increase with rapid ageing that makes cancer control in the next decade a crucial health domain [4].

The OIC has a diverse and contrasting socio-economic and human development index (HDI) profile, encompassing some of the least developed regions in the world, e.g., Sub-Saharan Africa and some of the wealthiest and most developed countries in the Arabian Gulf. It also faces challenges from conflicts, e.g., Syria and Yemen. OIC member states collectively host the world's largest demographically transitioned refugee populations, for which cancer control is a significant issue [5]. In light of these challenges, the OIC and subsidiary bodies such as the Islamic Development Bank (IsDB) have galvanised support among Muslim majority countries for global health objectives [16, 7]. Initiatives such as the Global Muslim Philanthropy Fund for Children [8] and the OIC 2025: Programme of Action have also been launched to enhance the efforts by OIC member states to achieve the sustainable development goals including cancer control [9].

The importance of cancer control for OIC becomes apparent because of 18.1 million new cancer global diagnoses in 2018 , and $10 \%$ were in OIC member states [10,11], as were $12 \%$ of global cancer deaths [4]. The rising burden of cancer was acknowledged at the 13th OIC Summit in Istanbul in April 2016 with the Istanbul Declaration against cancer under the auspices of the First Ladies' Leadership on Cancer Control [4]. As a part of the Istanbul Declaration, the Research for Health in Conflict partnership (r4hc-mena.org) committed to providing research evidence to inform not only the widely distinct political research economies of OIC member states but also key research funders such as the IsDB and the African Development Bank [12]. The main objective of this analysis is to provide information about one of the critical pillars of cancer control, namely research. Insights into relative strengths and weaknesses of cancer research across the OIC can be used by both national policy-makers and more widely within supranational OIC strategies to support new approaches to building research ecosystems.

\section{Methodology}

\section{Search strategy}

Articles and reviews in cancer research in 2008-17 with an address in one of the 57 OIC countries were identified in the Web of Science (WoS, (c) Clarivate Analytics). They were identified by means of a previously validated search filter (ONCOL) based on 185 specialist cancer journals and 323 title words or phrases, which included the names of cancers, drugs used to treat them and genes that increased (or decreased) the risk of cancer $[13,14]$. Papers were selected if they were in a cancer journal or had one or more of the listed words or phrases or both. [Cancer journals were included if $90 \%$ (or more) of their papers had one of the listed title words.] The precision (specificity) of the filter was $p=0.95$ and the recall (sensitivity) was $r=0.98$, so the true number of cancer papers was $0.95 / 0.98=0.97$ times the apparent number. All the papers identified by the filter were retained, and their details were downloaded to a spreadsheet and saved for 50 that had been retracted. There was no language restriction. 
This was carried out in September 2018, by which time the tally of 2017 papers would have been effectively complete. The 5-year citation scores (actual citation impact, $\mathrm{ACl}$ ) for the papers from 6 years, 2008-13, were also determined from the WoS separately and copied and pasted to the file of papers.

\section{Analysis of countries and subjects}

The addresses on the papers were analysed by means of a Visual Basic for Applications program to show the fractional counts of the countries. For example, a paper with two Turkish addresses and one from France would be classed as TR $=0.67$ and FR $=0.33$. To put the research outputs of the different countries in context, they were plotted against the healthcare expenditures of the leading OIC states. [We also tried plotting them against the wealth and populations of the OIC countries.] As the outputs of the leading OIC states had been increasing quite rapidly in recent years and as, in 2015, the WoS was expanded to process many additional journals published outside North America and Western Europe, we used outputs in 2015-17 and compared them with healthcare expenditures for 2015.

We also applied two special filter programs to the papers' titles and journal names in order to classify them by the anatomical cancer site(s) investigated by the authors and the type of research (e.g., genetics, surgery and palliative care) [14]. We used a similar methodology to identify papers that concerned the clinical trials or paediatrics. We compared the overall OIC outputs on major cancer sites with the relative collective disease burden in DALYs from cancers on each site in 2010. [Data for the disease burden in 2015 are available, but the amount of research in 2008-17 would not have been much influenced by them.] Outputs on different anatomical sites or research types were also cross-tabulated by the fractional counts of the leading OIC countries (i.e., the 15 with the largest outputs of cancer research papers) so as to show which ones were relatively specialising on particular sites or research types.

We also wished to see the amount of international collaboration in cancer research by the OIC countries. For this purpose, we calculated the fractional count contributions of the leading OIC countries to their papers, and the corresponding contributions by other OIC countries, by Canada and the USA, the EUR31 countries (the 27 member states of the European Union + Iceland, Norway, Switzerland and the UK) and the Rest of the World.

\section{Analysis of funding}

A further analysis was of the funding of these cancer research papers. Since 2009, the Science Citation Index, a major component of the Web of Science, has recorded the funding acknowledgments on the papers it includes. However, the names of the individual explicit funders are given in a number of different formats, so we use three-character (trigraph) codes to identify them, together with two digraph codes to connote their sector (government, non-profit, commercial and international) and their nationality [15]. We recorded the numbers of funders per paper and the percentage of papers, which acknowledged explicit funding, for the OIC papers with and without third-country collaboration as a function of time. We also coded for the analysis of the major funding sources in 10 non-OIC countries who collaborated on these papers and also the main governmental and academic (university) funding sources in 10 leading OIC countries.

\section{Analysis of citations}

The citation counts of the papers in the first 5 years beginning with the year of their publication, $\mathrm{ACl}$, were multiplied by the fractional contributions of each country to each paper, and the totals were then divided by the fractional counts of the countries' contributions. The papers were also sorted by their $\mathrm{ACl}$ values, and the top 5\% of the whole cohort for the 6 years from 2008 to 2013 identified; they were cited 29 times or more. The percentages of each country's citable papers that received this number of citations or more, on a fractional count basis, were then calculated as percentages, divided by the average for the OIC of 5\% and then multiplied by 100 to give a 'world scale' value [16]. This gives an alternative ranking of the OIC countries based on their presence among the most cited papers although this is normally fairly similar to one based on mean $\mathrm{ACl}$ values. 


\section{Results}

\section{Cancer research outputs}

The total number of papers in the file was 49,712 over the decade $2008-17$, of which authors from OIC countries contributed a total of 41,064 (83\%), and the remainder came from EUR31 countries (7.4\%), Canada and the USA (5.7\%) and the rest of the World (4.3\%). The gross output of OIC cancer research papers rose from 2470 in 2008 to 8,387 in 2017 or by a factor of 3.4. However, the biggest year-onyear increase was from 5,297 in 2014 to 6,923 in 2015 when the WoS increased its coverage of journals from OIC countries (and others), as shown in Figure 1.

Overall, the top four cancer research-active OIC countries were Turkey (TR), with 15,269 papers in 2008-17, Iran (IR with 8,374), Egypt (EG with 4,330) and Malaysia (MY with 2,466). The output from most countries grew at about 14\% per annum over the decade, but it was much higher in Qatar (QA +35\% p.a.) and Indonesia (ID +29\% p.a.) and lower in Turkey (+8.2\% p.a.), Nigeria (NG +7.5\% p.a.) and, especially, Tunisia ( $\mathrm{TN}+2.3 \%$ p.a.) and actually negative in Kuwait (KW, $-3.8 \%$ p.a. [For most OIC countries with small outputs, an annual percentage increase is not meaningful.]

A comparison of country outputs in 2015-17, for those with at least 10 papers, with their healthcare expenditures in 2015, is shown in Figure 2 (Libya and Syria are omitted as GDP data were not available). Tunisia, Egypt and Turkey were relatively the most productive, with more than four times the output that would be expected based on the least-squares correlation line, whereas Sudan, Algeria and Indonesia were relatively the least research-active, compared with their national healthcare expenditures. The correlation with a power-law least squares line (based on all the OIC countries, for which the data were available) is positive and fairly good $\left(r^{2}=0.57\right)$ It is much better than for a plot of research outputs against GDP (for which $\left.r^{2}=0.29\right)$, against population $\left(r^{2}=0.03\right)$, or with a plot of papers per million population against the countries' HDI for which $r^{2}=0.06$.

\section{International collaboration}

Figure 3 shows the amounts of international collaboration for the 15 leading OIC countries, ordered by the percentage of foreign contributions to their papers. These range from nearly $62 \%$ for Qatar (QA) down to $9 \%$ for Turkey. The OIC countries collaborate very little with each other. For these 15 countries, only $4.4 \%$ of their outputs come from others in the total group of the 56 other countries, compared with Canada and the USA, and the EUR31 countries. The largest intra-OIC collaborations are for Saudi Arabia (SA, 16.3\%), the United Arab Emirates (AE, 12.8\%), Qatar (QA, 11.7\%) and Egypt (EG, 9.1\%).

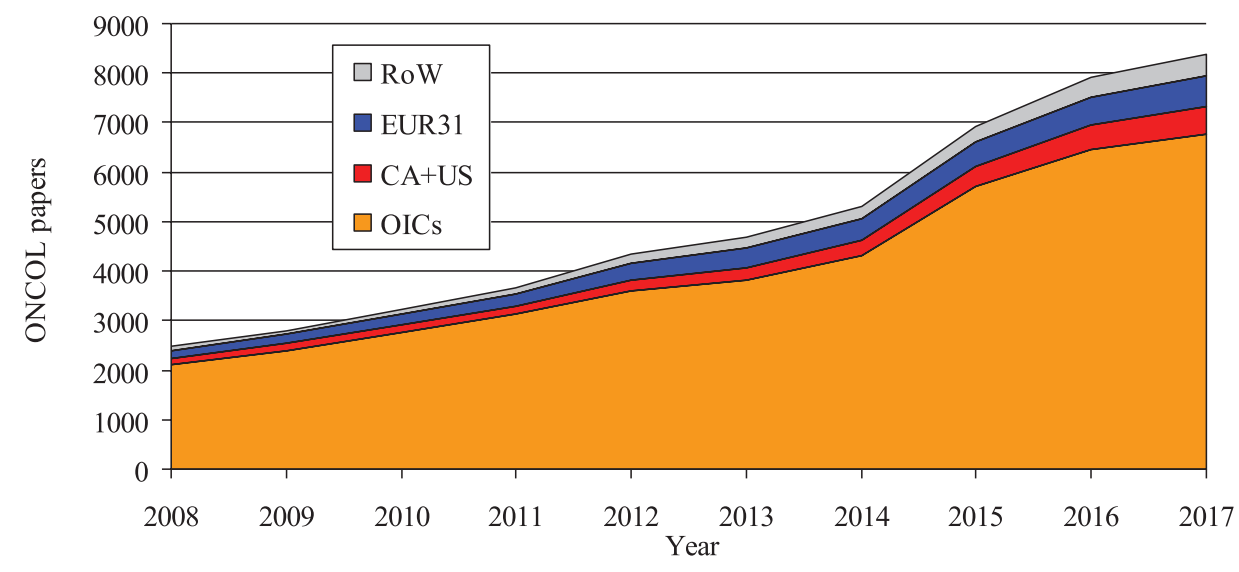

Figure 1. Outputs of cancer research papers in the WoS from the OIC countries, 2008-17, showing the contributions from Canada + USA, the EUR31 countries and the rest of the World (RoW). Note the big increase from 2014 to 2015 caused by the increase in journal coverage of the WoS. 


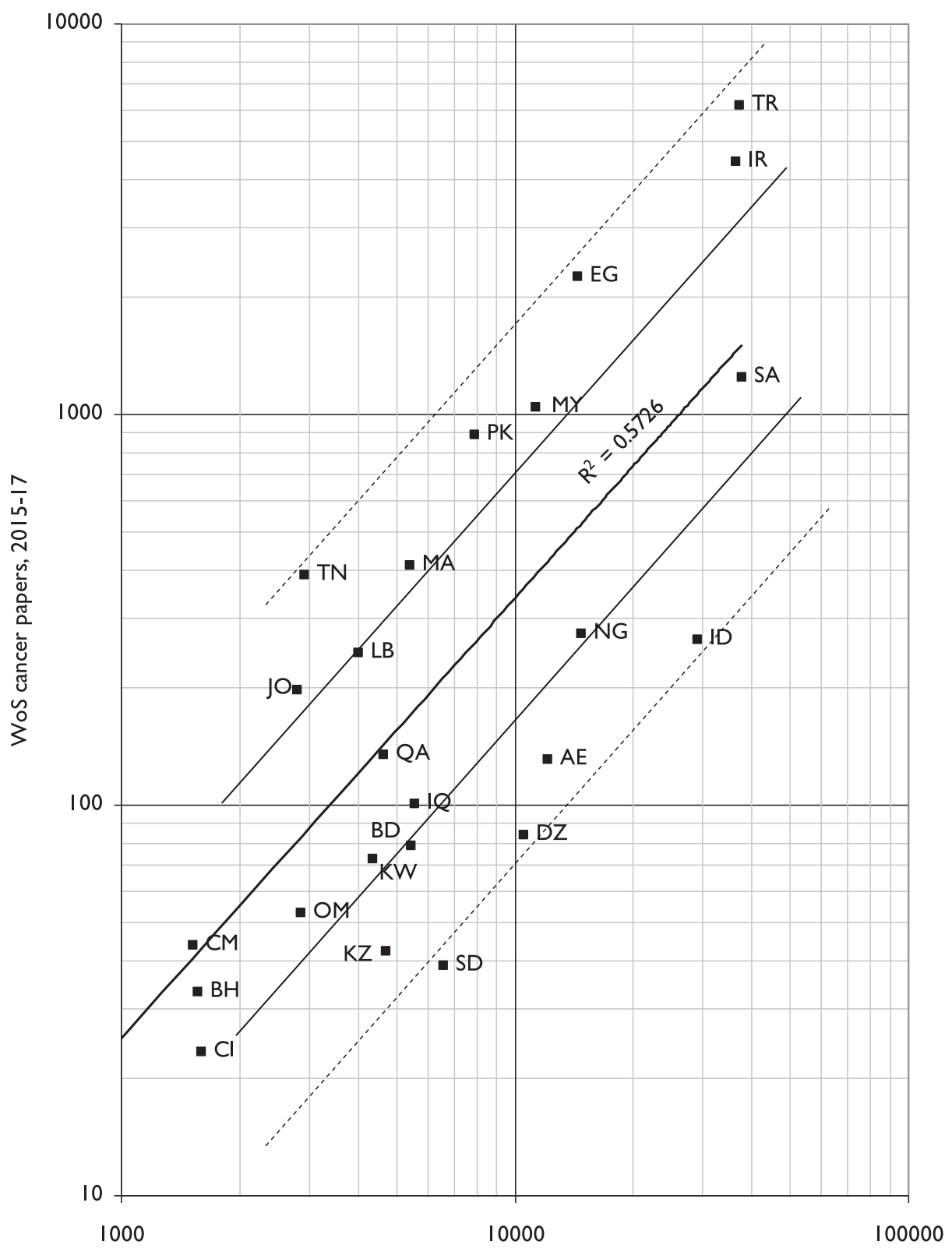

Total healthcare expenditure 2016, \$ M

Figure 2. Plot of cancer research papers from 24 leading OIC countries in 2015-17, fractional counts, against their healthcare expenditures in 2016, US \$ million. Log-log scales. For ISO2 codes, see Table 1. 


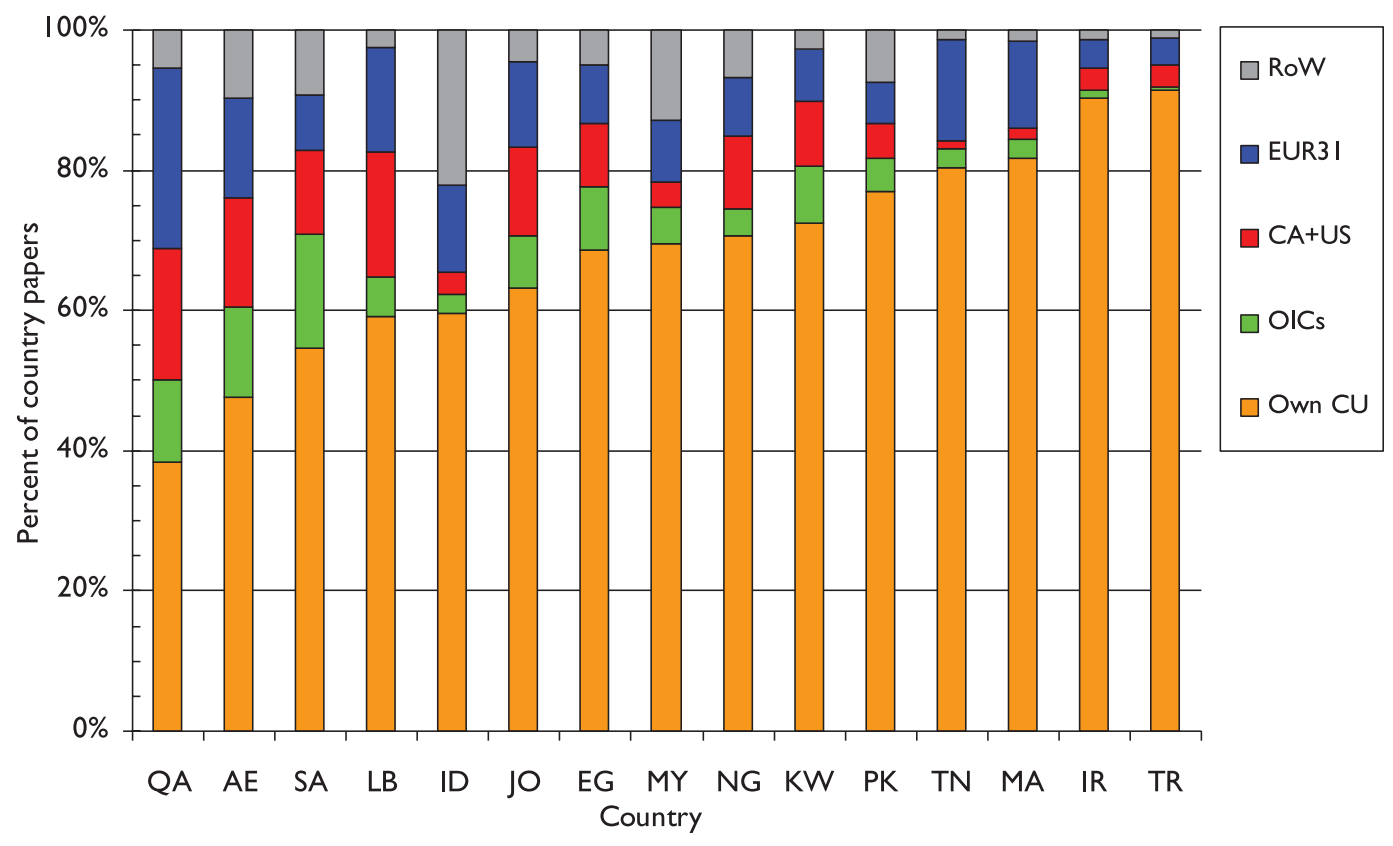

Figure 3. The proportion of outputs through collaboration by the leading OIC countries with others in the group, Canada and the USA, the EUR31 countries and the rest of the World (RoW), for 2008-17. For ISO2 country codes, see Table 1.

\section{Specialisation of OIC countries on cancer sites and research types}

Figure 4 shows the number of papers (integer counts) on each of the major cancer sites, together with their disease burden for the OIC countries in 2010. The different OIC countries varied in the percentages of their overall cancer research outputs that were relevant to each cancer site, relative to the percentages shown in Figure 4. There were 2,985 papers on children's cancer (6.0\%), reflecting the relatively high burden from paediatric cancers in the OIC countries (8.4\% of their overall cancer burden in DALYs, compared with $2.4 \%$ in European countries).

Table 2 shows the relative concentration of the leading $15 \mathrm{OIC}$ countries on research on the different anatomical sites. The figures compare each country's fractional production compared with that of all 57 OIC countries. For example, breast cancer (MAM) accounted for $13.3 \%$ of all OIC cancer papers and Malaysia (MY), which published a total of 2,466 cancer research papers, would have been expected to publish 327 on breast cancer. Its actual total was 501 papers, 1.53 times the expected value, and the difference was statistically highly significant ( $p<0.01 \%$ on the Poisson distribution with one degree of freedom). Gynaecological cancers (GYN) were calculated as the total of cervical, fallopian tube, ovarian, uterine and vulva cancers. The cells are tinted in five bands, chosen to show minor $(>\sqrt{ } 2$ or $<1 / \sqrt{ } 2)$ and major $(>2$ or $<0.5)$ departures from the 'norm' value of unity.

Figure 5 shows that the type of research most published by the $57 \mathrm{OIC}$ countries as a group was genetics, with over $16 \%$ of the total, followed by prognosis (biomarker-related research) and chemotherapy with $10 \%$ and surgery with $9 \%$. Radiotherapy research accounted for just $4 \%$ of papers. Palliative care research only represented $1.3 \%$ of the total OIC output; it was concerned primarily with breast cancer patients (120 out of 657 papers, or 18\%) and children (78 papers, 12\%). The distribution of OIC cancer research papers between the different research types is almost exactly the same as that in Europe (EUR31; $r^{2}=0.97$ ) [14]. Table 3 shows the relative commitment to particular domains of cancer research across the 15 research-active countries, which is prepared similarly to Table 2. 
Table 1. List of the OIC countries, with their ISO2 codes, populations in 2015 (million) and their GDPs per caput in that year (US dollars).

\begin{tabular}{|c|c|c|c|c|c|c|c|}
\hline Countries & ISO2 & Pop & GDP/caput & Countries & ISO2 & Pop & GDP/caput \\
\hline U Arab Emirates & $\mathrm{AE}$ & 8.1 & 44640 & Morocco & MA & 32.6 & 3080 \\
\hline Afghanistan & AF & 33.4 & 670 & Mali & $\mathrm{ML}$ & 16.3 & 820 \\
\hline Albania & $\mathrm{AL}$ & 3.2 & 4450 & Mauritania & MR & 3.6 & 1370 \\
\hline Azerbaijan & $A Z$ & 9.4 & 7600 & Maldives & MV & 0.4 & 8260 \\
\hline Bangladesh & BD & 152.4 & 1080 & Malaysia & MY & 29.3 & 11120 \\
\hline Burkina Faso & $\mathrm{BF}$ & 17.5 & 690 & Mozambique & $M Z$ & 24.5 & 620 \\
\hline Bahrain & $\mathrm{BH}$ & 1.4 & 20860 & Niger & NE & 16.6 & 420 \\
\hline Benin & BJ & 9.4 & 890 & Nigeria & NG & 167 & 2970 \\
\hline Brunei & $\mathrm{BN}$ & 0.4 & 31590 & Oman & OM & 2.9 & 18340 \\
\hline Cote d'Ivoire & $\mathrm{Cl}$ & 20.6 & 1450 & Pakistan & PK & 180 & 1400 \\
\hline Cameroon & $\mathrm{CM}$ & 20.5 & 1350 & Palestine & PS & 4.6 & 3090 \\
\hline Djibouti & DJ & 0.9 & 1030 & Qatar & QA & 1.9 & 92320 \\
\hline Algeria & DZ & 36.5 & 5490 & Saudi Arabia & SA & 28.7 & 25500 \\
\hline Egypt & EG & 84.0 & 3210 & Sudan & SD & 37.2 & 1710 \\
\hline Gabon & GA & 1.6 & 10410 & Sierra Leone & SL & 6.1 & 770 \\
\hline Guinea Bissau & GW & 1.6 & 590 & Senegal & SN & 13.1 & 1025 \\
\hline Gambia & GM & 1.8 & 460 & Somalia & SO & 9.8 & 728 \\
\hline Guinea & GN & 10.5 & 470 & Surinam & SR & 0.5 & 9590 \\
\hline Guyana & GY & 0.8 & 4036 & Syria & SY & 21.1 & 1850 \\
\hline Indonesia & ID & 245 & 3630 & Chad & TD & 11.8 & 980 \\
\hline Iraq & IQ & 33.7 & 6410 & Togo & TG & 6.3 & 550 \\
\hline Iran & IR & 75.6 & 6550 & Tajikistan & TJ & 7.1 & 1350 \\
\hline Jordan & JO & 6.5 & 4590 & Turkmenistan & TM & 5.2 & 7530 \\
\hline Kyrgyzstan & KG & 5.4 & 1260 & Tunisia & $\mathrm{TN}$ & 10.7 & 4035 \\
\hline Comoros & KM & 1.0 & 555 & Turkey & TR & 74.5 & 10630 \\
\hline Kuwait & $\mathrm{KW}$ & 2.9 & 49300 & Uganda & UG & 35.6 & 670 \\
\hline Kazakhstan & $\mathrm{KZ}$ & 16.4 & 12475 & Uzbekistan & UZ & 28.1 & 2070 \\
\hline Lebanon & LB & 4.3 & 8120 & Yemen & YE & 25.6 & 1330 \\
\hline Libya & LY & 6.5 & 7820 & & & & \\
\hline
\end{tabular}

There were only 684 clinical trial papers (1.4\%), for all four phases: this is fewer than the world average (3.2\%) in the same years and much below the percentages in Canada (7.8\%) and the four leading European countries (France, Germany, Italy and the UK $=9.6 \%$ ). In the nine years (2009-17) for which funding data in the WoS were available, only 314 out of 654 clinical trial papers (48\%) had a financial acknowledgment, and of these, only 111 acknowledged support from a pharmaceutical or biotech company (17\% of the total). 


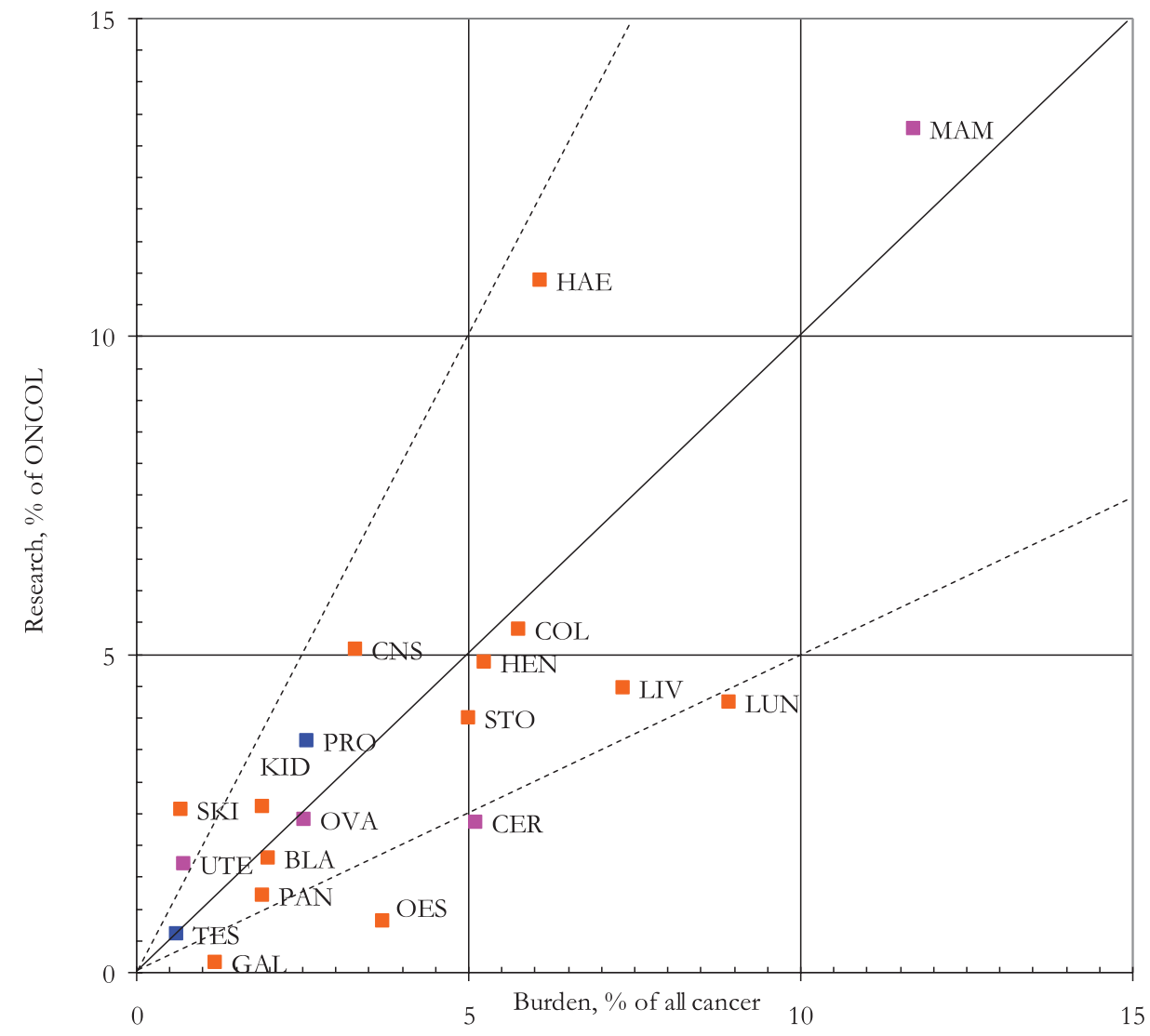

Figure 4. Percentages of all OIC cancer research papers, 2008-17, on individual cancer sites (integer counts) plotted against their collective burden (in DALYs; WHO data for 2010). (Blue spots: male cancers; pink spots: female cancers.) BLA=Bladder; CER=Cervix; CNS=Central nervous system; $\mathrm{COL}=$ Colon and rectum; GAL = gall bladder; HAE = Haematology; HEN=Head and Neck; KID = Kidney; LIV = Liver; LUN = Lung; MAM = Breast; OES = Oesophagus; OVA = Ovary; PAN = Pancreas; PRO = Prostate; SKI = Skin (incl. Melanoma); STO = Stomach; TES = Testicles; UTE = Uterus.

\section{Analysis of funding acknowledgments}

The percentage of OIC cancer research papers in 2009-17 without contributions from non-OIC countries rose from $16 \%$ in 2009 to $32 \%$ in 2017: this rise is partly an artefact because the WoS increased its coverage of acknowledgments over the period. The corresponding percentages for papers with third-country collaboration rose from $54 \%$ to $65 \%$. It is also clear that the latter have many more funding acknowledgments, by a factor of two, or even more in the early years of the study period. The mean number of funders was only 1.3 for the non-collaborative papers but rose steadily from 2.6 to 4.4 for the ones with a non-OIC co-author.

It also appeared that there was relatively little explicit contestable funding for the OIC researchers, and their predominant sources of support were from their university funds rather than from government agencies running competitive support schemes (Table 4). This was particularly true for Iran, where universities were acknowledged more than ten times as often as government agencies. However, a few OIC countries received more support from government departments and agencies than they did from universities (notably Tunisia and Pakistan, but also Indonesia and Bangladesh). None of them had any significant sources of charitable funding (either collecting charities or endowed 
foundations) which are common in Western Europe, North America and Australasia. The African Development Bank was acknowledged on only ten papers and the IsDB on seven of them. The leading non-OIC funders were the US government departments and agencies (e.g., the National Cancer Institute), who, in total, supported about 7.6\% of all the OIC papers and charitable sources (e.g., Cancer Research UK and the Wellcome Trust). A support from industrial companies (led by Hoffman La Roche s.a., Novartis s.a., Sanofi-Aventis s.a. and Merck Inc.) only amounted to about $1.9 \%$ of the papers, compared with $6.6 \%$ in Europe [14].

\section{Analysis of citations}

The final analysis was of citations to papers published in 2008-13 for the OIC countries. The mean ACl for most of the individual OIC countries is below the average value $(\mathrm{ACl}=9.0)$ for the whole set of OIC cancer research papers and well below the world average 5 -year citation score of 16 cites in these years. The results are shown in Table 5, with the countries ranked by their 'World-Scale' performance, i.e., the proportion of their papers with enough cites to put them in the top $5 \%$ of all the OIC papers, which is 29 cites or more. This is calculated relative to the mean of 100 . WS is below average for IR and all the countries below it in the table, but even the better performing countries' presence among the top $5 \%$ is not significant on the Poisson distribution with one $\mathrm{d} / \mathrm{f}$. Indonesia (ID) performs well in terms of mean $\mathrm{ACl}$ probably because $27 \%$ of its citable papers are co-authored with the Netherlands and $29 \%$ with Japan. Qatar (QA) also does well, as $89 \%$ of its citable papers are internationally co-authored, two-fifths of them with the USA.

Table 2. Relative output within cancer research to work on 11 cancer sites (codes below Figure 2) by the leading 15 countries (see Table 1), $2008-17$. Cells where this ratio $>2.0$ tinted green; $>1.41$ tinted pale green; $<0.71$ tinted yellow; $<0.50$ tinted pink. Values where the difference between the observed and expected values is statistically significant at $p<0.05$ are shown in bold type.

\begin{tabular}{|l|l|l|l|l|l|l|l|l|l|l|l|}
\hline & MAM & HAE & GYN & PED & COL & CNS & HEN & LIV & LUN & STO & PRO \\
\hline TR & 0.83 & 1.19 & 1.25 & 1.40 & 0.90 & 1.36 & 1.09 & 0.87 & 1.57 & 1.40 & 1.15 \\
\hline IR & 1.24 & 0.86 & 0.78 & 0.74 & 1.08 & 0.78 & 0.90 & 0.57 & 0.52 & 1.13 & 0.87 \\
\hline EG & 0.78 & 0.93 & 0.67 & 0.99 & 0.79 & 0.63 & 0.56 & 2.78 & 0.72 & 0.76 & 0.61 \\
\hline MY & 1.53 & 0.73 & 0.99 & 0.42 & 1.69 & 0.57 & 1.28 & 0.72 & 0.58 & 0.41 & 0.71 \\
\hline SA & 1.07 & 0.72 & 0.76 & 0.66 & 1.44 & 0.96 & 1.21 & 1.28 & 0.82 & 0.75 & 0.77 \\
\hline PK & 1.07 & 0.94 & 0.94 & 0.64 & 0.57 & 0.71 & 1.46 & 1.04 & 0.57 & 0.52 & 0.93 \\
\hline TN & 0.89 & 1.00 & 0.86 & 0.98 & 1.37 & 1.05 & 0.93 & 0.84 & 1.23 & 0.96 & 0.58 \\
\hline MA & 0.82 & 1.05 & 1.25 & 1.07 & 0.73 & 1.50 & 1.45 & 0.94 & 1.67 & 1.23 & 0.38 \\
\hline NG & 1.25 & 0.74 & 1.98 & 1.46 & 0.45 & 0.65 & 1.48 & 0.50 & 0.38 & 0.44 & 1.84 \\
\hline LB & 0.96 & 2.10 & 0.39 & 1.66 & 1.51 & 1.01 & 0.77 & 0.77 & 0.88 & 1.59 & 1.10 \\
\hline JO & 1.36 & 1.11 & 0.65 & 2.11 & 1.33 & 1.06 & 0.85 & 0.13 & 0.49 & 0.18 & 0.97 \\
\hline ID & 1.37 & 0.61 & 1.61 & 1.14 & 0.95 & 0.45 & 1.03 & 0.80 & 0.65 & 0.32 & 1.21 \\
\hline AE & 1.39 & 0.74 & 0.94 & 0.85 & 0.96 & 0.74 & 0.71 & 1.08 & 0.79 & 1.16 & 0.42 \\
\hline KW & 1.43 & 1.33 & 0.49 & 1.11 & 1.05 & 1.20 & 1.31 & 0.41 & 0.74 & 0.49 & 0.43 \\
\hline QA & 1.31 & 1.19 & 1.42 & 0.43 & 1.30 & 0.78 & 0.32 & 0.68 & 0.65 & 0.52 & 1.16 \\
\hline Total & 6593 & 5416 & 3092 & 2985 & 2687 & 2525 & 2421 & 2229 & 2113 & 1990 & 1806 \\
\hline
\end{tabular}




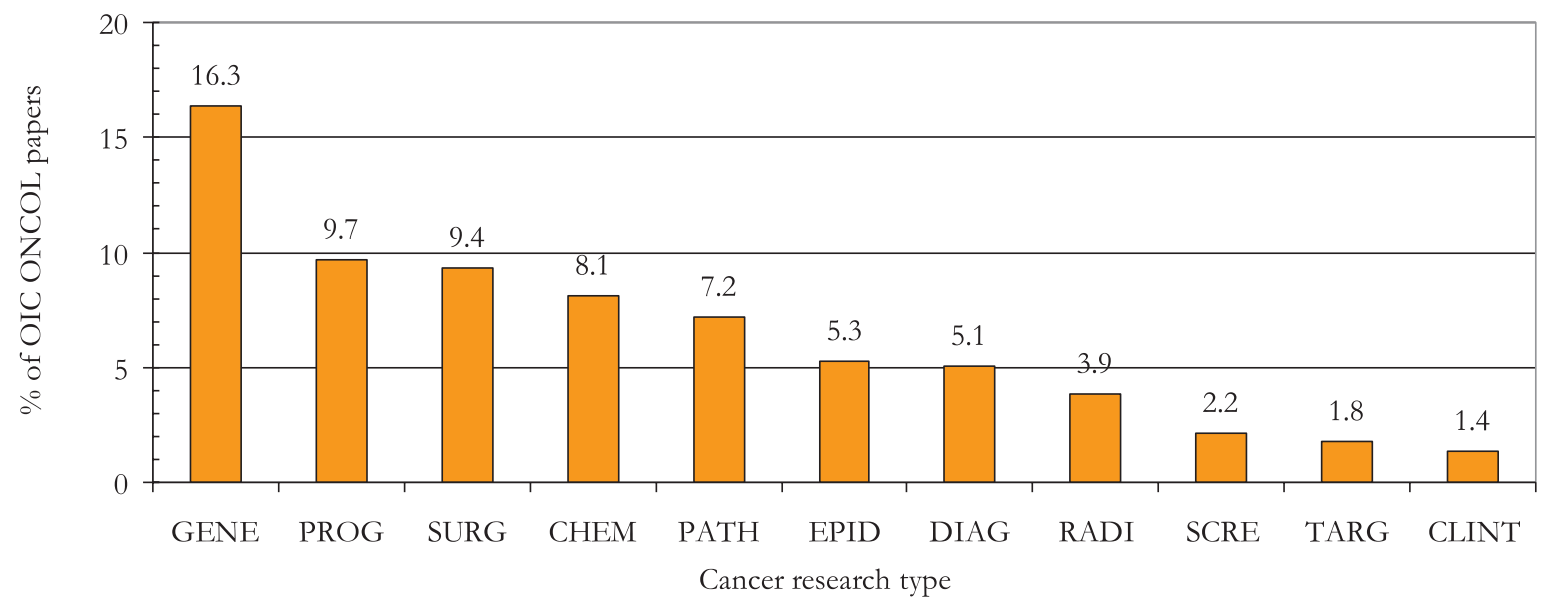

Figure 5. Percentages of OIC countries' cancer research, 2008-17, in 12 domains. GENE = genetics; PROG = prognosis; CHEM = chemotherapy; SURG = surgery; $\mathrm{PATH}=$ pathology; $\mathrm{EPID}$ = epidemiology; DIAG = diagnosis; RADI = radiotherapy; SCRE = screening; CLINT = clinical trials.; PALL = palliative care; QUAL = quality of life.

Table 3. Relative output within cancer research of work on 10 research types (codes below Figure 5) by the leading 15 countries (see Table 1), $2008-17$. Cells where this ratio $>2.0$ tinted green; $>1.41$ tinted pale green; $<0.71$ tinted yellow; $<0.50$ tinted pink. Values where the difference between the observed and expected values is statistically significant at $p<0.05$ are shown in bold type.

\begin{tabular}{|l|l|l|l|l|l|l|l|l|l|l|}
\hline & GENE & PROG & CHEM & SURG & PATH & EPID & DIAG & RADI & SCRE & CLINT \\
\hline TR & 0.81 & 1.16 & 1.07 & 1.61 & 0.99 & 0.69 & 1.25 & 1.63 & 0.80 & 0.63 \\
\hline IR & 1.26 & 0.78 & 1.26 & 0.50 & 0.82 & 1.11 & 0.81 & 0.55 & 0.86 & 1.20 \\
\hline EG & 1.05 & 1.28 & 1.12 & 0.97 & 1.25 & 0.62 & 1.26 & 0.87 & 0.72 & 1.66 \\
\hline MY & 1.13 & 0.65 & 0.73 & 0.46 & 0.99 & 1.05 & 0.59 & 0.41 & 1.91 & 0.66 \\
\hline SA & 1.03 & 0.80 & 1.02 & 0.71 & 1.06 & 0.88 & 0.78 & 0.58 & 1.20 & 0.60 \\
\hline PK & 0.88 & 0.93 & 0.79 & 0.70 & 1.19 & 1.32 & 1.23 & 0.78 & 0.83 & 0.29 \\
\hline TN & 1.43 & 0.93 & 0.42 & 0.69 & 1.57 & 1.51 & 0.73 & 0.95 & 0.70 & 0.60 \\
\hline MA & 0.70 & 0.36 & 0.42 & 1.71 & 0.89 & 0.67 & 1.15 & 1.45 & 0.79 & 0.31 \\
\hline NG & 0.37 & 0.52 & 0.62 & 1.16 & 0.77 & 1.43 & 1.15 & 1.13 & 3.74 & 0.41 \\
\hline LB & 0.68 & 0.86 & 1.30 & 1.19 & 0.63 & 0.84 & 0.52 & 1.20 & 0.69 & 1.68 \\
\hline JO & 0.89 & 0.91 & 0.86 & 0.98 & 1.00 & 1.40 & 1.04 & 0.92 & 1.27 & 0.20 \\
\hline ID & 1.43 & 0.83 & 1.18 & 0.84 & 0.59 & 1.42 & 0.66 & 0.74 & 1.06 & 0.98 \\
\hline AE & 1.02 & 0.98 & 1.09 & 0.68 & 1.19 & 1.10 & 0.86 & 0.64 & 1.15 & 0.42 \\
\hline KW & 1.04 & 0.38 & 0.67 & 0.46 & 2.05 & 0.50 & 2.12 & 0.71 & 1.10 & 0.10 \\
\hline QA & 0.76 & 1.02 & 0.64 & 0.84 & 0.53 & 1.45 & 0.70 & 0.55 & 2.11 \\
\hline Total & 8124 & 4804 & 4799 & 4652 & 3578 & 2633 & 2529 & 1923 & 1071 & 684 \\
\hline
\end{tabular}


Table 4. Numbers of funding acknowledgments to universities (UNIV) and government departments and agencies (GOV) in 10 leading OIC countries and to government (GOV) and private-non-profit funders (PNP, collecting charities and endowed foundations) in 10 leading non-OIC countries, on OIC cancer research papers, 2009-17.

\begin{tabular}{|c|c|c|c|c|c|c|c|}
\hline \multicolumn{4}{|c|}{ OIC countries } & \multicolumn{4}{|c|}{ Non-OIC countries } \\
\hline Country & ISO2 & UNIV & GOV & Country & ISO2 & GOV & PNP \\
\hline Iran & IR & 3931 & 352 & United States & US & 3575 & 1130 \\
\hline Turkey & TR & 1735 & 865 & United Kingdom & UK & 1024 & 1260 \\
\hline Malaysia & MY & 1328 & 917 & France & FR & 625 & 352 \\
\hline Saudi Arabia & SA & 1285 & 169 & Germany & DE & 534 & 346 \\
\hline Egypt & EG & 241 & 230 & Netherlands & NL & 392 & 241 \\
\hline Pakistan & PK & 105 & 278 & Canada & CA & 359 & 267 \\
\hline Tunisia & $\mathrm{TN}$ & 21 & 330 & Italy & IT & 275 & 345 \\
\hline Lebanon & LB & 116 & 65 & Spain & ES & 431 & 87 \\
\hline Indonesia & ID & 51 & 77 & Japan & $J P$ & 395 & 64 \\
\hline Bangladesh & BD & 18 & 26 & China & $\mathrm{CN}$ & 388 & 0 \\
\hline
\end{tabular}

Table 5. Citation performance (five-year, fractional country counts) for cancer research papers from the 15 leading OIC countries in terms of arithmetic mean values ( $\mathrm{ACl}$ mean) and presence in the top $5 \%$ (29 cites or more). Cells where this ratio $>1.41$ tinted pale green; $<0.71$ tinted yellow; $<0.50$ tinted pink. Numbers of papers with 29+ cites that are significantly below the values expected shown in bold type. For country codes, see Table 1.

\begin{tabular}{|c|c|c|c|c|c|c|c|}
\hline \multirow[t]{2}{*}{ Country } & \multirow[t]{2}{*}{ Citable papers } & \multirow[t]{2}{*}{ Cites } & \multirow[t]{2}{*}{$\mathrm{ACl}$ mean } & \multicolumn{3}{|c|}{ Top 5\% } & \multirow[t]{2}{*}{ W.S. $5 \%$} \\
\hline & & & & Expected & Observed & Sign. & \\
\hline SA & 917 & 8939 & 9.8 & 45.8 & 57.8 & n.s. & 125 \\
\hline QA & 40 & 536 & 13.3 & 2.0 & 2.4 & n.s. & 117 \\
\hline $\mathrm{AE}$ & 150 & 1399 & 9.3 & 7.5 & 8.6 & n.s. & 114 \\
\hline LB & 259 & 2259 & 8.7 & 12.9 & 12.9 & n.s. & 99 \\
\hline ID & 86 & 941 & 10.9 & 4.3 & 4.3 & n.s. & 98 \\
\hline EG & 1615 & 15056 & 9.3 & 80.8 & 78.1 & n.s. & 96 \\
\hline JO & 209 & 1546 & 7.4 & 10.5 & 9.3 & n.s. & 88 \\
\hline MY & 1119 & 9438 & 8.4 & 56.0 & 49.6 & n.s. & 88 \\
\hline IR & 3030 & 23722 & 7.8 & 151.5 & 115.4 & $0.25 \%$ & 76 \\
\hline PK & 785 & 4020 & 5.1 & 39.3 & 15.1 & $0.01 \%$ & 38 \\
\hline NG & 286 & 1524 & 5.3 & 14.3 & 5.3 & $1.50 \%$ & 37 \\
\hline TR & 7479 & 39326 & 5.3 & 373.9 & 111.8 & $0.00 \%$ & 30 \\
\hline $\mathrm{TN}$ & 630 & 3054 & 4.8 & 31.5 & 7.7 & $0.00 \%$ & 24 \\
\hline KW & 172 & 947 & 5.5 & 8.6 & 2.1 & $2.36 \%$ & 24 \\
\hline MA & 401 & 1348 & 3.4 & 20.1 & 3.7 & $0.01 \%$ & 19 \\
\hline
\end{tabular}


Table 6. The numbers of cancer researchers from five Levantine countries: United Arab Emirates (AE), Jordan (JO), Kuwait (KW), Oman (OM) and Qatar (QA) in 2015-17 from different ethnic or national backgrounds, based on the Origins database classification of names into ten geographical regions.

\begin{tabular}{|c|c|c|c|c|c|c|c|c|}
\hline Countries & Code & $\mathrm{AE}$ & JO & KW & OM & QA & Total & $\%$ \\
\hline Other Muslim countries & MUS & 154 & 269 & 89 & 93 & 166 & 771 & 39.4 \\
\hline Levant including Turkey & LEV & 74 & 207 & 41 & 40 & 102 & 464 & 23.7 \\
\hline Western Europe & EUR & 60 & 29 & 23 & 13 & 80 & 205 & 10.5 \\
\hline Maghreb* + Egypt & MED & 43 & 51 & 12 & 7 & 46 & 159 & 8.1 \\
\hline Bhutan, India, Nepal, Sri Lanka & IND & 50 & 10 & 21 & 25 & 36 & 142 & 7.3 \\
\hline Africa (Sub-Saharan) & $A F R$ & 26 & 55 & 13 & 9 & 15 & 118 & 6.0 \\
\hline Eastern Europe incl. Russia & EEU & 13 & 12 & 5 & 1 & 11 & 42 & 2.1 \\
\hline Not known & UNK & 5 & 12 & 5 & 0 & 5 & 27 & 1.4 \\
\hline East Asia & EAS & 9 & 1 & 0 & 0 & 5 & 15 & 0.8 \\
\hline \multirow[t]{2}{*}{ Latin America } & LAT & 3 & 1 & 0 & 4 & 4 & 12 & 0.6 \\
\hline & Total & 437 & 647 & 209 & 192 & 470 & 1955 & \\
\hline
\end{tabular}

*The Maghreb consists of Algeria, Libya, Mauritania, Morocco and Tunisia.

\section{Discussion}

As a political group, the OIC countries shoulder a significant and growing global burden of new cancer cases and cancer deaths [11]. The ratio of deaths from cancer to the number of new cases is 0.62 in the OIC countries as a group but only 0.46 in Europe and 0.29 in North America and Oceania. These data show that treatment in the OIC countries, particularly those in Africa, lags significantly behind that available in other parts of the world. The burden of cancer is only set to grow as countries complete their demographic and epidemiological transitions. Furthermore, globalisation also increases OIC countries' risk from increasing exposure to procancer risk factors such as tobacco [6, 7].

National cancer research activity is important for two reasons. First, it enables these countries to apply and adapt international treatment standards based on national burden and practice, and second, it can provide better career prospects to aid the retention of research-active cancer healthcare workers in the OIC and reduce the amount of emigration [18]. The provision of a high-quality medical research culture in a country will also attract international collaborations, which have become increasingly important for complex large-scale clinical trials. As a political group, the OIC is well placed in terms of both advocacies for cancer control across the vastly different member countries but also to leverage capacity and capability funding to build both mature and nascent cancer research systems within the National Cancer Control Plans. This will require radically different policy approaches.

The $57 \mathrm{OIC}$ countries are very heterogeneous in terms of their cancer research outputs, with a factor of almost 90,000 between the most productive (Turkey, TR) and the least (Turkmenistan, TM). The developed countries of Western Europe show a close correlation between their cancer research outputs and their GDPs as do the countries of Eastern Europe and the former Soviet Union [14, 19]. However, the correlation for the OIC countries between GDP and cancer research output is much weaker, and the research correlates better with healthcare expenditure (Figure 2). Again, this speaks to the need for a more formal central co-ordination and advocacy role for the OIC.

The analysis suggests that there are two broad groups of countries in terms of cancer research. Some publish many papers, notably in TR, Iran (IR), Egypt (EG) and Malaysia (MY) and far fewer in the UAE (AE), Indonesia (ID) and Sudan (SD). However, some countries well below the regression line have been severely affected by conflict, notably Kuwait and Yemen. In addition, OIC countries in Sub-Saharan Africa [Nigeria (NG), Sudan (SD), Côte dılvoire (Cl) and Burkina Faso (BF)] are also performing well below what would be expected. For the latter three which fall into the fragile and low-income categories, this is to be expected, but Nigeria stands out as a key example of where there is an urgent need to significantly improve cancer research for a major emerging power. 
The strong showing of the OIC countries in genetics research (Figure 5), which is relatively basic, which is relatively basic, seems at odds with what is needed to inform national cancer control planning. Instead, it reflects the Western-dominated bias towards this research domain. One might have expected proportionately more research on screening and diagnosis and the means of treatment, such as surgery and radiotherapy. The widely different relative concentration of some countries on particular research types shown in Table 3 suggests that more international collaboration would be advantageous for those countries that are under-researching them.

We wondered if this distortion of the research agenda in favour of a pattern more suited to industrial countries might be caused by the research cadres in some of the small middle eastern countries having a high proportion of immigrants. We, therefore, listed the names of the cancer researchers in 2015-17 in five countries: the UAE, Jordan, Kuwait, Qatar and Oman. With the aid of a proprietary database of names, Origins, these were classed in 10 geographical groups. Table 6 shows the numbers of individuals in each group, after those listed with only initials were amalgamated with those whose given names were also given in the WoS. The allocation to the groups, "Levant including Turkey", "Maghreb plus Egypt" and "Other Muslim countries", was disputable as their Arab-sounding names appeared rather similar, and indeed, only about $8 \%$ of the names were classed as coming from the five countries. It is clear that immigrants only represented about a quarter of the total-western Europeans being the most numerous at 10\% overall but 14\% in the UAE and 17\% in Qatar. However, Table 3 shows that genetics was not a priority for research in either country.

The funding analysis, though preliminary, showed that there was very little explicit contestable funding available in the OIC countries (except to their non-OIC partners). This is not a recipe for the production of high-impact research. It may also be one of the reasons for the lack of international collaboration shown in Figure 3, except for Qatar, the UAE and Saudi Arabia, whose generous funding has attracted foreign partners. It may also account for the relatively poor citation performance on the global scale. The overall citation performance of the OIC countries $(\mathrm{ACl}=9.0$ cites in five years) is significantly lower than the global average, which was 16.3 in 2009 . The relatively low citation rate for Turkey and Iran, the two largest OIC countries in terms of output, warrants further examination by national policy-makers. Notably, international collaborations in these countries are scarce, accounting for less than $10 \%$ of their output, but there is also a lack of contestable funding sources.

Many OIC countries have had to allocate resources to combat more prevalent communicable diseases and NCDs such as cardiovascular disease. They have younger populations and have failed to respond adequately to cancer, which is catching up as a major driver of mortality. Limited resources are made available at the national level to fund cancer research in these countries and, even when present, are channelled to genetic research. Clinical research in cancer is critical in these countries but severely lacking. Late-stage cancer diagnosis remains a major problem, and research into detection encompassing early diagnosis and screening should be prioritised. Patients diagnosed with cancer in these settings often get lost navigating the healthcare system, and local solutions may only be available if research is undertaken in this area [20,21]. Cancer survival in many OIC countries also appears to be significantly lower than many equivalent non-OIC countries [22], and the importance of improving cancer research ecosystems must be the key future strategy. Furthermore, cancer survivorship care is neglected as most health systems tend to be focussed on the provision of treatment and the management of short-term side effects from adjuvant cancer therapy. Findings from the ASEAN Costs in Oncology (ACTION) study, which included Malaysia and Indonesia, have shown that patients surviving cancer in the region continued to have persistently impaired health-related quality of life and high levels of psychological distress $[23,24]$. Again, these are domains that lack any research focus across most OIC countries.

\section{Limitations of this study}

One of the main limitations in this study is that the data were obtained from a single source, which may be less comprehensive in its coverage of papers from these countries than some others, such as MedLine or SCOPUS. However, MedLine only records the address of the corresponding author so would have failed to show the lack of internationalism of the OIC countries and would have omitted those, where the corresponding author was in a non-OIC country. The choice of the WoS rather than SCOPUS was primarily because of the availability of extensive software that enabled us to carry out the analysis efficiently. Moreover, the presence of additional papers in possibly less influential journals would have adversely affected the OIC countries' citation scores. 


\section{Conclusion}

The analysis demonstrates that cancer care remains under-researched across much of the OIC, and urgent action is needed to bolster cancer control. The Istanbul Declaration provided a useful framework to unite OIC member states, prioritise cancer in their health and development agenda and increase collaboration between member states and international organisations such as the UN and the World Health Organisation (WHO). Ongoing capacity-building efforts, e.g., Research for Health in Conflict ( $r$ hhc-mena.org) including cancer prevention programmes as well as technical and material assistance to improve early detection, diagnosis and treatment are welcome, but it is imperative that the significant deficits in cancer research output are addressed now. The OIC as a political body should strengthen existing collaborative networks, form new research and health policy partnerships and work collectively to address key research and policy issues both at national and trans-OIC levels.

\section{Acknowledgments}

The authors are grateful to Philip Roe for the provision of macros (Visual Basic for Applications programs for MS Excel) that enabled us to carry out the analysis herein described.

\section{Conflicts of interest}

The authors declare no conflicts of interest.

\section{Funding}

This publication is funded through the UK Research and Innovation GCRF RESEARCH FOR HEALTH IN CONFLICT (R4HC-MENA); developing capability, partnerships and research in the Middle and Near East (MENA) ES/P010962/1.

\section{References}

1. Ibrahim A (2019) All you need to know about the OIC [Internet] Al Jazeera [cited 3 December 2019] https://www.aljazeera.com/ news/2019/05/oic-190531055450527.html Date accessed: 3/12/19

2. OIC (2019). History [Internet] https://www.oic-oci.org/page/?p_id=52\&p_ref=26\&lan=en Date accessed: 3/12/19

3. SESRIC (2019) A brief on the organisation of Islamic Cooperation (OIC) and its institutions [Internet] Date accessed: 3/12/19

4. Kutluk T, Ataş E, and Gültekin M, et al (2018) Cancer control in member countries of Organization of Islamic Cooperation (OIC)-a status report \& İstanbul declaration by the first ladies of OIC J Cancer Policy 18 25-32 https://doi.org/10.1016/j.jcpo.2018.10.003

5. Abdul-Khalek RA, Guo P, and Sharp F, et al (2020) The economic burden of cancer care for Syrian refugees: a population-based modelling study Lancet Oncol 21(5) 637-644 https://doi.org/10.1016/S1470-2045(20)30067-X PMID: 32359488

6. Islamic Development Bank (2013) IDB group reiterates commitment to healthcare in member countries at global vaccine summit [Internet] https://www.isdb.org/news/idb-group-reiterates-commitment-to-healthcare-in-member-countries-at-global-vaccine-summit Date accessed: 8/12/19

7. Hussain SF, Boyle P, and Patel P, et al (2016) Eradicating polio in Pakistan: An analysis of the challenges and solutions to this security and health issue Global Health 12(1) https://doi.org/10.1186/s12992-016-0195-3 PMID: 27729081 PMCID: 5059991 
8. UNICEF (2019) UNICEF and the Islamic Development Bank launch first global Muslim philanthropy fund for children [Internet] https:// www.unicef.org/press-releases/unicef-and-islamic-development-bank-launch-first-global-muslim-philanthropy-fund

9. OIC (2016) The OIC 2025: programme of action [Internet] https://www.oic-oci.org/docdown/?docID=16\&refID=5

10. Jemal A et al. (2016) The Cancer Atlas (Atlanta: American Cancer Society)

11. SESRIC (2016) Status of cancer in OIC member countries [Internet] http://www.sesric.org/files/article/544.pdf

12. Akinwande B and Nitzsche A. (2018) The Programme of Action for Cancer Therapy of the International Atomic Energy Agency, the Islamic Development Bank, and the Organization of Islamic Cooperation (Alexandaria: American Society of Clinical Oncology)

13. Lewison G (2011) Definition of cancer research: journals, titles, abstracts or keywords? DESIDOC J Libr Inf Technol 31(5) 333-339 https://doi.org/10.14429/djlit.31.5.1189

14. Begum M, Lewison G, and Lawler M, et al (2018) Mapping the European cancer research landscape: An evidence base for national and Pan-European research and funding Eur J Cancer 100 75-84 https://doi.org/10.1016/j.ejca.2018.04.017 PMID: 30014883

15. Begum M and Lewison G. (2017) Web of science research funding information: methodology for its use in analysis and evaluation $J \mathrm{Sci}$ Res 6(2) 65-73 https://doi.org/10.5530/jscires.6.2.12

16. Lewison G, Thornicroft G, and Szmukler G, et al. (2007) Fair assessment of the merits of psychiatric research Br J Psychiatry 190(4) 314-318 https://doi.org/10.1192/bjp.bp.106.024919 PMID: 17401037

17. Hussain Z and Sullivan R. (2017) Tobacco in post-conflict settings: the case of Iraq Ecancermedicalscience 11735 https://doi.org/10.3332/ ecancer.2017.735 PMID: 28596801 PMCID: 5440183

18. El Saghir NS, Anderson BO, and Gralow J, et al (2020) Impact of merit-based immigration policies on brain drain from low-and middleincome countries JCO Glob Oncol 6(2) 185-189 https://doi.org/10.1200/JGO.19.00266 PMID: 32023124 PMCID: 7051246

19. Begum M, Lewison G, and Jassem J, et al (2018) Mapping cancer research across Central and Eastern Europe, the Russian Federation and Central Asia: Implications for future national cancer control planning Eur J Cancer 104 127-136 https://doi.org/10.1016/j. ejca.2018.08.024 PMID: 30347288

20. El Saghir NS, Abou-Sitta G and Kaddoura I. (2017) Conflict medicine and cancer care in refugees and displaced people [Internet] ASCO Connection https://connection.asco.org/blogs/conflict-medicine-and-cancer-care-refugees-and-displaced-people Date accessed: 29/04/19

21. Dewachi O (2017) Ungovernable Life: Mandatory Medicine and Statecraft in Iraq (Palo Alto: Stanford University Press)

22. Allemani C, Matsuda T, and Di Carlo V, et al (2018) Global surveillance of trends in cancer survival 2000-14 (CONCORD-3): analysis of individual records for 37513025 patients diagnosed with one of 18 cancers from 322 population-based registries in 71 countries Lancet 391(10125) 1023-1075 https://doi.org/10.1016/S0140-6736(17)33326-3 PMID: 29395269 PMCID: 5879496

23. ACTION Study Group (2017) Health-related quality of life and psychological distress among cancer survivors in Southeast Asia: results from a longitudinal study in eight low-and middle-income countries BMC Med 15(1) 10 https://doi.org/10.1186/s12916-016-0768-2

24. Subramaniam S, Kong YC, and Chinna K, et al (2018) Health-related quality of life and psychological distress among cancer survivors in a middle-income country Psycho-oncology 27(9) 2172-2179 https://doi.org/10.1002/pon.4787 PMID: 29856903 